\title{
LAS ORGANIZACIONES DE MUJERES MAPUCHE EN EL CHILE DE LA REVUELTA
}

\author{
Millaray Painemal Morales ${ }^{244}$ \\ Susana Huenul Colicoy ${ }^{245}$
}

\section{Introducción ${ }^{246}$}

Durante el mes de marzo me invitaron a escribir sobre las organizaciones de mujeres mapuche y su relación con las organizaciones de mujeres y feministas no mapuche. Lo primero que se me vino a la cabeza fue "esto no lo puedo escribir sola. Además, lo deberían escribir compañeras mapuche que puedan reflexionar críticamente sobre la relación con las feministas”. Lo conversé con quienes me invitaron, acogieron la preocupación y me contacté con dos mujeres mapuche que desde sus organizaciones y territorio podían mirar esta relación desde sus distintas experiencias de participación en lo social y en el trabajo. Millaray Painemal Morales de Cholchol, dirigenta nacional de ANAMURI, y Susana Huenul Colicoy, profesional de la oficina de mujeres de la Municipalidad de Tirúa e integrante de la Comunidad de Historia Mapuche, aceptaron la invitación a escribir.

Mi acercamiento a las organizaciones de mujeres de pueblos originarios es reciente, hace ocho años tuve una experiencia muy gravitante como profesional y activista feminista. En el contexto de reconstrucción post 27F me tocó hacer un taller para la Asociación de mujeres tejedoras Relmu Witral de Tirua, con el objetivo de transferir y fortalecer capacidades, y transferir herramientas para el levantamiento de una agenda ciudadana y la generación de estrategias para la incidencia política. En esa actividad pude constatar que la metodología WINKA que llevaba para trabajar

\footnotetext{
244 Investigadora independiente millaraypainemal@yahoo.es 
con ellas era muy inadecuada y que los ejemplos de experiencias de incidencia que llevaba para que ellas diseñaran la propia, tenían poco o nada que ver con su forma de relacionarse con otras organizaciones y autoridades políticas y sociales del territorio. Gracias a esta experiencia aprendí que las dinámicas de relacionamiento en cada territorio son distintas y que no por el hecho de ser todas mapuche y tener entre sus actividades principales el tejer, se organizaban de la misma forma. Cada una tenía su grupo y cada uno de estos sus tiempos, conversaciones, intereses y necesidades. Es, a propósito de este trabajo — que se extiende hasta el día de hoy - que logro cuestionar día a día lo hegemonizantes que pueden resultar algunos feminismos y la ceguera cognitiva con la que nos relacionamos muchas veces con lo territorial. En varias ocasiones me he visto poniendo una voz de alerta en espacios feministas - algunos más institucionalizados que otros- sobre la mirada que existe de los territorios: "falta organización", "hay que ir a resolver los problemas", "es allá donde nos necesitan", entre otras expresiones, que muestran la ignorancia que tenemos sobre lo que está ocurriendo hace muchos años en los territorios. Las reflexiones de Millaray Painemal y Susana Huenul nos permiten ver aquello.

Este capítulo es una mirada que tiene su fortaleza y legitimidad desde las voces situadas de dos mujeres mapuche que reivindican la lucha de su pueblo por la autodeterminación y recuperación territorial, entendiendo esta última como una necesidad para estar, sentir y comprender el mundo desde un territorio específico. En este documento se ha definido que en las autoras hay un conocimiento y saber situado ${ }^{247}$ e insurgente ${ }^{248}$, un "sentipensar" 249 que se funda en lo ancestral y campesino, que por siglos - y reeditándose $\mathrm{e}^{250}$ - se ha expresado como política de resistencia frente a un capitalismo neoliberal, colonialista y patriarcal.

247 Relacionado al concepto de conocimiento situado, en él "las personas sentimos, pensamos, expresamos y actuamos a partir de lo que hayamos acumulado en nuestras historias de vida, dependiendo de los contextos sociales, geográfico-políticos, culturales, nuestras pertenencias sociales, familiares, nuestras herencias emocionales, subjetivas y ancestrales. El procesamiento de todo ello es lo que determina la manera como articulamos nuestra experiencia y, a partir de allí, el conocimiento que seamos capaces de reproducir desde una particular visión del mundo, lo situamos en un contexto (Aguilar, 2019:1).

248 "Nosotros corazonamos que el levantamiento del 90 impulsó la irrupción no solo de otra epistemología, sino de una forma de cosmocimiento que está más allá de ella: la sabiduría, pues, en realidad, como lo mostró esta acción colectiva, lo que estamos viviendo es un proceso de insurgencia de las sabidurías insurgentes, que rebasan los marcos epistemológicos dominantes y sus límites, y abren posibilidades para que estas sabidurías y espiritualidades, que se habían mantenido clandestinas, empiecen a visibilizarse. Sabiduría y espiritualidad que las "cosmunidades invisibles" que fueron creadas desde el mismo momento de la Conquista por las guardianas y los guardianes de la tierra, supieron preservar a través de los siglos en el corazón, la palabra y la acción de ancianas sabias y ancianos sabios y que, ahora, en tiempos en los que la Madre Tierra está muy enferma y amenazada, emergen para ser compartidas con la humanidad entera, como medicinas necesarias para sanar la existencia" (Guerrero, 2018:63).

249 Julieta Kirkwood miraba con sospecha aquel paradigma científico "reconocido", patriarcal, que puede poner en cuestión el orden establecido, ideado y pensado por este mismo. Un conocimiento que no admite aquellos conocimientos que por la forma en que se producen, a través de la experiencia, o por su contenido (mujer, amor, entre otros), resultan "perturbadores de la armonía del saber" y que se "atreven a postular ordenamientos teóricos alternativos" (Kirkwood, 2017:56). El sentipensar "muestra claramente el sentido político que tiene el encuentro entre el sentimiento y el pensamiento, y que es parte de la cosmo-existencia de las comunidades de las culturas del caribe colombiano, en donde un pescador le habló a Borda del sentipensar que se encontraba en el espíritu del "hombre hicotea que sabe ser aguantador para enfrentar los reveses de la vida y poder superarlos, que en la adversidad se encierra para volver luego a la existencia con la misma energía de antes, es también el hombre sentipensante que combina la razón y el amor, el cuerpo y el corazón, para deshacerse de todas las (mal) formaciones que descuartizan esa armonía y poder decir la verdad" (Moncayo, 2009:9, en Guerrero, 2018:26).

250 En contextos con adversarios diferentes, que actúan desde una razón colonialista y de conquista rapiña. 
¿Qué significó que tantas y tantos chilenos en Santiago tomaran la bandera mapuche para expresar su rebeldía ante el sistema en la revuelta social de octubre del 2019? En este gesto había una profunda valoración a un pueblo con historia de resistencia al despojo territorial y la brutal dominación, represión y domesticación de los cuerpos y sexualidades a propósito del proceso de colonización. Las y los chilenos habían "despertado" y eran capaces de impugnar a la institucionalidad que sostiene a un sistema cuya reproducción se juega en la injusticia y el abuso sobre determinados cuerpos (pobres, excluidos/as, mujeres precarizadas, cuerpos feminizados, niños/as, ancianos/as, entre otros).

Desde estas políticas de resistencia podemos ver, además, como se tejen historias ${ }^{251}$, un proyecto político, social, cultural y económico alternativo al capitalismo neoliberal extractivista, individualista, patriarcal, racista y colonialista.

Es así que algunos feminismos comienzan a hablar de la necesidad de un sistema nacional plurinacional de cuidados, abrazando la organización de las y los mapuche frente a los cuidados. Las comunidades mapuche le asignan un valor fundamental a las tareas de cuidado, a todo aquello que reproduce socialmente la vida. Ellos y ellas han colectivizado los cuidados, algo que los y las no mapuche estamos aprendiendo a propósito de la experiencia de la pandemia: para existir debemos valorar la experiencia del coexistir y esto solo es posible en torno al cuidado mutuo.

Por otro lado, es importante preguntarse ¿qué hay detrás de la violencia institucional sostenida contra las hortaliceras de Temuco? ¿Qué es lo que el Estado busca reprimir ahí? Las hortaliceras son una expresión de resistencia a la opresión capitalista neoliberal, patriarcal y racista, así como también, quienes ponen de manifiesto, en su forma de producir y comercializar, un modelo de sociedad y economía alternativo, y que hoy quienes habitamos la ciudad, estamos valorando mucho más a propósito de la pandemia.

En definitiva, lo que está en juego son modelos de sociedad y formas de coexistencia (de hacer política) distintos. Susana Huenul nos permite ver la forma en la que actualmente funciona el Estado y, por ende, la construcción de democracia y ciudadanía que hay detrás de aquello. Un Estado que no logra acercarse a la realidad que viven cientos de mujeres víctimas y sobrevivientes de violencia patriarcal en el campo, con distancias geográficas donde se hace necesario un Estado más cercano, más pertinente y con capacidades que permitan a la o el funcionario público, diseñar y ejecutar la acción pública con un enfoque de derechos humanos, interseccional e intercultural.

En la escritura de Millaray y de Susana queda claro que no es posible pensar el Estallido o revuelta social de octubre del 2019 como un evento particular en nuestra historia política y social de post dictadura cívico y militar, así como tampoco del proceso histórico, político, social y cultural de colonización. Los saberes insurgentes y las historias tejidas dan cuenta de que en el territorio mapuche se vive hace siglos en permanente revuelta y

251 Tejer historias desde la vida es un acto de profundo compromiso político con una realidad no pensada, sino intensamente vivida y que ha inscrito en la profundidad de los espíritus, los cuerpos y las memorias una multiplicidad de dolores, alegrías, sueños y luchas, que son las que hacen el vivir, a fin de compartir esos procesos, desde la afectividad, desde el corazón y poder transformar esa vida, desde la cual se habla (Guerrero, 2018:39). 
que, a diferencia de muchas organizaciones y movimientos sociales que comienzan post Estallido con un proceso destituyente en cabildos y cabildas, reuniones barriales y huertas comunitarias, entre otras expresiones sociales y políticas que permitieron pensar en el nuevo Chile que podríamos levantar, las comunidades mapuche - fundamentalmente aquellas que viven en Wallmapu - tenían una definición más clara de la sociedad en l que quieren coexistir, porque llevan muchos años viviéndola de manera subalternizada.

La forma en que organizamos la escritura fue a través de preguntas que orientaron la reflexión en torno a tres grandes temas: las voces de las mujeres mapuche frente a los nuevos mundos posibles que estamos construyendo; políticas de resistencia al modelo hegemónico desde los sentipensares situados; y las voces silenciadas, no escuchadas de las organizaciones de mujeres mapuche, ideas, sueños y proyecto de sociedad alternativo al que hoy vivimos.

\section{Reflexiones en tiempos de crisis}

\section{Millaray Painemal Morales, dirigente de la Red de Mujeres Mapuche Trawun pu Zomo y de Anamuri}

Comienzo este escrito posicionándome como mujer mapuche, activista y defensora de los derechos de las mujeres y del Pueblo Mapuche. No es mi afán ni pretendo hablar por todas las mujeres mapuch raza aborigen y unir a todas las araucanas existentes en esta ciudad con fines puramente culturales"252.

En la actualidad, son numerosas las organizaciones de mujeres articuladas tanto en las zonas urbanas como rurales; algunas trabajan al alero de municipalidades y otras de manera más autónoma. Las motivaciones son variadas y diversas, por un lado, enfrentar las políticas asimilacionistas del Estado chileno y, por otro, las diversas situaciones de racismo y discriminación, y la violencia de género que proviene desde la propia sociedad mapuche y de la chilena.

Las mujeres de las comunidades luchamos junto al movimiento mapuche para denunciar la instalación de proyectos extractivistas en nuestros territorios, como son las hidroeléctricas, los vertederos, las carreteras y leyes como el Tratado Transpacífico o TTP11 y su intento de privatizar las semillas, base de la soberanía alimentaria.

Hoy en día, las comunidades se encuentran en un proceso de recuperación territorial, lo que ha generado un conflicto latente entre el Pueblo Mapuche y el Estado, y la consecuente persecución y encarcelación de líderes mapuche. La represión judicial de la protesta se lleva a cabo bajo una Ley Antiterrorista que se origina en el periodo de la dictadura militar de Pinochet.

En este contexto de despojo territorial, las mujeres mapuche también han sufrido persecución. Entre ellas, la Machi Francisca Linconao - defensora del territorio mapuche y de sus plantas medicinales- que fue encarcelada y luego dejada en libertad. No ocurrió lo mismo con la activista mapuche Macarena Valdés, quien fuera cobardemente asesinada 
en agosto del año 2016 en Tranguil, sur de Chile, por oponerse junto a su comunidad a la instalación en el territorio de una central de paso de la empresa RP Global.

En la actualidad, las comunidades de diversos territorios estamos enfrentando en lo cotidiano graves problemáticas como la sequía de nuestros pozos, esteros, ríos y la desaparición del bosque nativo, aves y diversas especies.

Es habitual ver que las familias mapuche reciban agua en camiones aljibe desde los municipios. Esto afecta profundamente la calidad de vida de las mujeres, de sus familias y de las comunidades. Otro tema de nuestro interés, es la recuperación de nuestras semillas nativas y que realizamos a través de los llamados Trafkintu, una práctica ancestral que antiguamente se hacía entre diversas comunidades y territorios. Un ejemplo de ello es que de la zona cordillerana donde habita el Pueblo Mapuche pewenche se traían los piñones a la zona de la costa y se intercambiaban por el trigo o las papas. El Trafkintu, ha sido y es una práctica social, económica, solidaria y espiritual que retomamos con fuerza las organizaciones de mujeres de las comunidades y que se ha expandido a las ciudades en espacios como escuelas, liceos y organizaciones sociales.

Es así que cada año a nivel local realizamos diversas actividades como nütram o conversatorios y seminarios para intercambiar conocimientos y promover la defensa y el cuidado de la madre tierra y los peligros existentes, como el calentamiento global y el actual sistema económico capitalista.

El año 2019 en la ciudad de Santiago, el actual Gobierno de Piñera pretendía realizar la cumbre sobre Cambio Climático llamada COP25. Sin embargo, esta no ocurrió, siendo cancelada producto de la situación de crisis social y económica por la que aún atraviesa el país.

En tanto, desde las organizaciones de mujeres campesinas e indígenas afiliadas a ANAMURI y a la Coordinadora Latinoamericana de Organizaciones del Campo, convocamos el día 10 de diciembre en Temuco a un seminario interregional denominado "Crisis Climática y Social, juntas y juntas enfriamos el planeta y proponemos alternativas al modelo neoliberal”. Aquí reflexionamos acerca de los fenómenos climáticos que están ocurriendo a nivel planetario y de sus efectos negativos en la pequeña agricultura familiar campesina y en la soberanía alimentaria de los pueblos. Otra de las temáticas expuestas tuvo que ver con la Asamblea Constituyente y el Estado plurinacional y paritario. Aquí, las mujeres campesinas e indígenas demandaron una nueva Constitución para el país que reconozca la plurinacionalidad.

Durante el Estallido Social, iniciado el 18 de octubre de 2019, las organizaciones vinculadas a ANAMURI nos sumamos a las grandes protestas y movilizaciones para exigir cambios políticos y sociales como derecho a la salud, educación, pensiones dignas y por una nueva Constitución plurinacional y paritaria. Sin embargo, esta última demanda no es compartida por toda la sociedad mapuche, pues algunos sectores plantean que su lucha principal es por la autonomía territorial del Pueblo Mapuche.

Asimismo, en Wallmapu se produjeron hechos como el derribamiento de estatuas de personajes históricos como Pedro de Valdivia y Cornelio Saavedra, entre otros, como símbolos de opresión y violencias hacia el Pueblo Mapuche. Es así que estas imágenes han quedado grabadas en nuestra memoria $y$ nos hablan del inicio de un proceso de 
descolonización de nuestras mentes y de una invitación a que los habitantes de Wallmapu comencemos a mirarnos, pensarnos, relacionarnos y tejernos de manera distinta.

Los saberes y conocimientos que hemos ido adquiriendo desde pequeñas se fortalecen en nuestra edad madura escuchando a los FUTAKECHE (ancianos y ancianas), aunque hoy en día muchos de ellos se encuentran viviendo solos, una problemática que debemos conversar al interior de nuestras familias y comunidades.

Antiguamente, las familias cuidaban de sus FUTAKECHE y sus voces eran muy respetadas, nos enseñaban acerca del respeto a la naturaleza, a escuchar, observar e interpretar sus señales. Una de estas señales se produjo en el mes de marzo del año 2019, cuando en algunas comunidades floreció la quila, lo que fue interpretado como "mala señal", de la llegada de graves problemas, enfermedades, escasez y hambruna. En el pasado, cuando esto ocurría, la gente hacía ceremonias invocando a los espíritus de la naturaleza y se preparaba con alimentos y medicinas.

Frente a la expoliación de los territorios es necesario establecer alianzas con otros sectores de la sociedad chilena, como ambientales, sindicales, de estudiantes y de mujeres diversas, y que se respeten nuestras propias formas de ver la vida, que tienen como base nuestra cosmovisión. En estos tiempos debemos recuperar y fortalecer nuestras prácticas ancestrales, entre ellas el Kelluzomowen o solidaridad entre mujeres (y ejercerlas), como lo hacían nuestras abuelas, que se ayudaban unas a otras. El siguiente testimonio lo ilustra.

Antes se vivía en grupos [...], las mujeres eran bien unidas, hacían todo junto, cuando pisaban el trigo, iban cantando [...]. En ese tiempo cuando le pegaban a una mujer, entre todas arrinconaban a los hombres y no era fácil que la pasaran a llevar, eran más respetadas. Ahora no pasa eso. (Testimonio Chiñura Morales, Cholchol, 2014, en Edit: Álvarez y Painemal,

2015:13)

El año 2019, las mujeres mapuche nos unimos en Temuco a la conmemoración del 8 de marzo, Día de la Mujer, y lo hicimos para apoyar las demandas de las mujeres feministas en su lucha contra la violencia patriarcal y contra el Estado que nos oprime y persigue también a nosotras. Hoy en día ha emergido con fuerza un movimiento feminista al cual respetamos y valoramos, pero no es algo que nos identifique plenamente, debido a que muchas de sus demandas no logran encajar con nuestra realidad y muchas veces se intentan imponer sus propias agendas, que para nosotras no son prioritarias.

Como mujeres mapuche hemos venido planteando que nuestra principal lucha es por la autonomía político-territorial y colectiva como pueblo, sin dejar de lado nuestros derechos específicos como mujeres, como es nuestra salud afectiva, sexual y reproductiva, tomando en cuenta nuestra cultura y cosmovisión.

No obstante, valoramos y reafirmamos la necesidad de seguir fortaleciendo las redes y alianzas con mujeres de distintos sectores del movimiento feminista, las cuales deben ser respetuosas y horizontales para construir una nueva sociedad diversa y erradicar el racismo y el patriarcado. Asimismo, como mujeres mapuche organizadas nos encontramos en un proceso de fortalecimiento interno, en que promovemos espacios de conversación entre mujeres diversas, tomando en cuenta las voces de las más ancianas y el traspaso de conocimiento a las más jóvenes. 
En el contexto de la crisis ambiental y sanitaria que vivimos a nivel mundial, reconocemos que nuestro principal enemigo es el capitalismo, causante de la depredación de nuestros bienes naturales: el agua, los árboles, las plantas medicinales y la desaparición de aves y animales. Es nuestro deber crear conciencia en la mayoría de la población que aún está adormecida y siente poco interés por el cuidado del planeta.

Nuestras voces se construyen en sintonía con la madre tierra, escuchando a los pájaros, a los árboles y a nuestros sueños, fortaleciendo, de esta manera, nuestro espíritu y nuestro entorno. Es a partir de estas voces que nos construimos y reconstruimos para caminar por este sendero llamado vida y al que todos y todas estamos convocados.

\section{Desafíos de la lucha por una vida libre de todo tipo de violencias}

\section{Susana Huenul Colicoy. Comunidad de Historia Mapuche}

Tomaré "la posta" de este texto conjunto, luego de la contundente reflexión de Millaray, compartiendo plenamente su análisis. En particular, lo mencionado respecto a la diversidad de las organizaciones de mujeres mapuche, y sobre los temas transversales y compartidos por esta diversidad de sectores de mujeres organizadas y no organizadas, ya sea en el campo, en la ciudad, en organizaciones ambientales, campesinas y juntas de vecines, por mencionar algunas. Da en el clavo cuando dice que apostamos por el Buen Vivir, como un principio guiado por la soberanía alimentaria, la agroecología y la defensa de nuestros derechos como mujeres y a una vida libre de todo tipo de violencias, cada uno grandes temas en sí mismos y relacionados entre sí.

Las descripciones y análisis de este escrito las realizo bajo una lógica de conocimiento situado que ha desarrollado la corriente feminista socialmente comprometida (Hernández, 2015:86), como trabajadora de la Oficina de Mujeres en la Dirección de Desarrollo Comunitario de la Municipalidad de Tirúa, a partir de lo que me ha tocado vivir y observar en diversas interacciones durante siete años ejecutando programas locales para el autosustento, acompañando mujeres y organizaciones, principalmente del campo, mediante la puesta en valor de los saberes locales, realizando iniciativas que cuiden y protejan el medio ambiente. En esto, la agroecología pasa a ser una potente herramienta, clave para potenciar factores protectores asociados al conocimiento de la huerta, las plantas, el bosque y el cuidado del agua, ya que, aun teniendo pocos recursos económicos, se puede acompañar procesos para y con las mujeres, que permitan avanzar hacia el autosustento. También me he vinculado con la temática de prevención de la violencia contra las mujeres, desde un rol de facilitadora y gestionadora de talleres con organizaciones y funcionarias/os públicos y a través de la coordinación de la Mesa Comunal por la No Violencia Contra la Mujer de Tirua, instancia que, según los lineamientos de SERNAMEG ${ }^{253}$, debiese ser coordinada por el Centro de la Mujer ${ }^{254}$. En nuestro caso, dado que no contamos

253 Servicio Nacional de la Mujer y la Equidad de Género.

254 En el contexto de elaboración de este capítulo, la Municipalidad de Tirúa y el Servicio Nacional de la Mujer y la Equidad de Género de la Región del Biobío se encuentran instalando el Centro de la Mujer de Tirúa. Dispositivo fundamental para la prevención y atención psicosocial y jurídica de las mujeres que están viviendo violencia patriarcal. 
con ese dispositivo, nos autoconvocamos mensualmente. Participan de este espacio la asociación de tejedoras Relmu Witral, Hogar de Cristo, Fundación Mi Casa, Liceo Trapaqueante y oficinas de la Municipalidad de Tirua vinculadas con el tema. Desde mayo de 2018 el municipio no cuenta con profesional del área psicosocial dedicada al abordaje de la violencia contra las mujeres, y si bien existe el Programa de Salud Mental del Centro de Salud Familiar (CESFAM), las profesionales no dan abasto con la demanda que existe. En este escenario, como mesa nos reunimos para trabajar en aquellas acciones que seamos capaces de asumir desde nuestras distintas funciones, tales como la sensibilización mediante talleres, redes sociales y radio, como también para compartir información, brindarnos apoyo y autoformarnos en ámbitos más específicos de lo que implica enfrentar la violencia contra las mujeres. Como hito, realizamos cada año una caminata y un acto simbólico en el marco del 25 de noviembre, Día Internacional de la Eliminación de la Violencia contra la Mujer, para visibilizar esta problemática en el pueblo de Tirúa. En el año 2019, las mujeres mapuche y no mapuche de Tirúa caminamos todas juntas detrás de un lienzo que decía "Ni la tierra ni las mujeres somos territorio de conquista". Este visibilizaba que la violencia hacia las mujeres está también determinada por el contexto y que desborda la idea de que la violencia solo ocurre en la casa y en la relación de pareja. El lienzo visibilizaba el impacto del violento proceso de colonización y la consecuente racialización de los cuerpos y el ejercicio de la sexualidad de las mujeres hasta el día de hoy. En base a esta experiencia compartiré algunas reflexiones en cuanto al actuar del Estado a través de los gobiernos locales y de la comunidad en esta materia, y profundizaré lo planteado por Millaray respecto a la defensa de nuestros derechos como mujeres y a una vida libre de todo tipo de violencias.

\section{Violencias contra las mujeres en territorios rurales}

En un intento de caracterizar las situaciones de violencias que viven las mujeres mapuche y no mapuche en el campo, considero - en primer lugar- aquellas violencias estructurales, marcadas por lógicas económicas. Tal es el caso de la presencia de la industria forestal y las grandes extensiones de monocultivo de árboles exóticos como el pino y el eucaliptus. Se ha difundido mucho acerca de los impactos socioambientales de los monocultivos de las plantaciones forestales en territorio mapuche (Araya, 2003; Aylwin, Yáñez y Sánchez, 2013) como consecuencia de la disminución de bosque nativo, esto es, afectación en la disponibilidad de agua para consumo humano y riego; afectación en la disponibilidad de frutos y hongos silvestres; afectación a los sistemas económicos de oficios asociados al bosque, como recolección y cestería; y desmedro de la salud mapuche, pues las hierbas medicinales (LAWEN) crecen en el bosque, no en el monocultivo, y se han visto disminuidas según reportan los agentes de salud mapuche que las recolectan para sanar a las comunidades (Huenul, 2017:310).

Otro ámbito de la violencia estructural ocasionada por la industria forestal, tiene que ver con el gasto estatal en policía para resguardar los intereses económicos de los 
dueños de las empresas ${ }^{255}$. Esto ha significado la progresiva militarización del territorio, en ascenso desde el año 2014. La presencia de las fuerzas policiales deja en evidencia que el objetivo es proteger intereses privados, como lo indican decenas de testimonios que hemos recogido donde se denuncia que Carabineros no acude cuando mujeres o testigos de la violencia patriarcal han llamado pidiendo ayuda.

Junto con lo anterior, existen otras características que afectan la vida de las mujeres. Tirúa, por ejemplo, es una comuna con una superficie de $624 \mathrm{~km}^{2}$ que presenta alta dispersión geográfica y baja conectividad hacia las zonas rurales, existiendo algunos sectores que cuentan con transporte subsidiado. Sumado a lo anterior, por la accidentada geografía de la cordillera de Nahuelbuta, la señal de teléfono también es débil. Estas son dos barreras de género que influyen en la problemática de violencia contra las mujeres dado que afectan, por ejemplo, la participación en organizaciones y/o talleres, la movilización a la ciudad a pedir ayuda, o poner una denuncia (física o virtualmente), contribuyendo al aislamiento y ausencia de redes que viven las mujeres víctimas de violencia.

Por lo anterior, planteamos que las mujeres que viven violencia en contexto de pareja en el territorio de Tirúa, viven triple discriminación. En primer lugar, por ser mujeres, luego por su condición de pobreza y exclusión, que constituye una barrera para solicitar ayuda y, tercero, por ser mapuche.

En cuanto a cómo hemos trabajado en prevención y abordaje de la violencia contra las mujeres, específicamente, en sensibilización, quisiera remontarme al año 2013 en que comencé a trabajar en la Municipalidad de Tirúa. Mi rol consistía en coordinar la Unidad de Familia en la Dirección de Desarrollo Comunitario, que estaba compuesta por la Oficina de Infancia, la del Adulto Mayor, la de Discapacidad y la de Mujeres, esta última también bajo mi responsabilidad. Asumí esta tarea con mucho compromiso ya que estaba muy motivada con trabajar en desarrollo comunitario. Dado que mi formación es en comunicación social, es decir, no me formé para ejecutar políticas públicas, intenté aplicar lo que había aprendido en el Programa Servicio País y en una maestría en antropología social que pude realizar gracias a una beca que obtuve el año 2008.

Durante la fase de diagnóstico, entre mayo y diciembre de 2013, se evidenció la necesidad de trabajar en sensibilización, pues en las distintas instancias de diálogo aparecían creencias y pensamientos asociados a justificar la violencia que vivían las mujeres, un rechazo a querer abordar el tema y pérdida de confianza en las instituciones por malas experiencias de quienes habían vivido violencia y habían denunciado. En cuanto a la atención de las víctimas, en ese tiempo el Centro de la Mujer (CDM) de Cañete tuvo por varios años un equipo relativamente estable y atendía casos en Tirúa y el Municipio de Cañete. Entre enero de 2014 y mayo de 2018 contó con una trabajadora social a cargo de recibir denuncias, acompañar y/o derivar casos de violencia y mantener activas las redes. Durante ese periodo realizamos permanentemente talleres con organizaciones y trabajadoras/ es municipales, conversatorios y puerta a puerta, en coordinación con el CDM de Cañete. Posterior a eso, han transcurrido dos años en que no se cuenta con dispositivos para atender a víctimas de violencia en contexto de pareja. Algo que 
probablemente viven muchas comunas de Chile y donde la forma de operar es cubrir la atención comunal en el CDM más cercano y de otra comuna. La particularidad de Tirúa es que lo hace en medio de un territorio atravesado por el conflicto del Estado de Chile con el Pueblo Mapuche, donde una de las principales formas de protesta es el corte y toma de caminos, impidiendo el traslado de las profesionales del CDM de Cañete o de las mujeres de Tirúa al CDM de Cañete. Esto fue alertado al Ministerio de la Mujer y la Equidad de Género post Estallido y revuelta social de octubre del 2019, porque estos cortes se hicieron más recurrentes y, por ende, se vio totalmente suspendida cualquier tipo de atención. En estos dos años, la Mesa Comunal por la No Violencia se ha mantenido trabajando en la tarea de sensibilización, pues para poder avanzar, debemos ir derrumbando los estereotipos de género que constituyen los patrones de pensamiento machista y la normalización de la violencia. En este contexto, hemos facilitado procesos para que -mediante metodologías participativas y dialogantes de trabajo, de compartir e intercambiar entre mujeresestas barreras se vayan derribando. En este camino una herramienta útil ha sido el enfoque de derechos, pues las conversaciones entre mujeres acerca de sus derechos, en un mediano plazo da como resultado que sean ellas mismas quienes identifiquen la violencia como una vulneración que no debe suceder.

Las conversaciones entre mujeres han sido y son una gran herramienta para ir avanzando hacia una vida sin violencia. Desde la cosmovisión mapuche tomamos la idea del nütram, de la conversación, para ir conociéndonos, generando confianzas y acompañarnos para crecer juntas.

En un encuentro de mujeres en el marco del Día Internacional de la Mujer de este año, organizado por la Red de Mujeres del Lavkenmapu y la Mesa por la No Violencia, en conversaciones grupales las mujeres identificaron la violencia económica y patrimonial, expresada en aquella dependencia económica que les dificulta salir de la dinámica de violencia. En cuanto a la violencia psicológica, sobresalen las referencias a "ninguneos" y menosprecios que viven algunas mujeres que se organizan o buscan desenvolverse en la vida pública. En cuanto a la violencia sexual, aparecen relatos asociados al control de la reproducción e identificaron también la violencia obstétrica. Las mujeres relatan lo traumático y violento que fueron sus partos por los tratos recibidos, por lo que valoran que se haya avanzado recientemente en este tema, dado que en el Hospital de Cañete existe la posibilidad de optar al parto respetado con pertinencia cultural. La violencia simbólica aparece asociada a la reproducción de estereotipos que sindican a las mujeres como responsables de la violencia que viven. La violencia física aparece como la más cotidiana de las violencias.

\section{¿Quiénes tienen responsabilidad y deber en la prevención de la violencia contra las mujeres?}

La prevención de la violencia contra las mujeres es un tema de derechos humanos a nivel internacional sobre el cual se han establecido tratados y convenios ratificados por los Estados parte de las Naciones Unidas. El Estado de Chile ha ratificado la Convención sobre la Eliminación de Todas las Formas de Discriminación (CEDAW), adoptada por la Asamblea General de Naciones Unidas el 18 de diciembre de 1979 (Decreto 789 del 27 de octubre de 1989) y la Convención Interamericana para prevenir, sancionar y erradicar 
la violencia contra la mujer (Decreto 1640 del 26 de septiembre de 1998), más conocida como la Convención Belém Do Paré, en 1994. La Convención Belém Do Paré, en lo referido a los deberes del Estado, exige actuar con la debida diligencia para prevenir, investigar y sancionar la violencia contra la mujer (art.7, letra f). Así también, consigna el suministro de los servicios especializados apropiados para la atención necesaria a la mujer objeto de violencia, por medio de entidades de los sectores público y privado, inclusive refugios, servicios de orientación para toda la familia, cuando sea el caso, y cuidado y custodia de los menores oportunos y el acceso efectivo a tales procedimientos (art. 8, letra d). Esta Convención es el principal respaldo para el diseño de políticas públicas, y los 109 Centros de la Mujer con los que cuenta el Estado de Chile son parte de la respuesta a los compromisos internacionales en materia de violencia hacia las mujeres.

De este modo, es evidente el rol de las políticas públicas de carácter centralizado y descentralizado, como herramientas para generar algunas de las transformaciones necesarias que permitan avanzar hacia un Buen Vivir de las mujeres. Se hace necesario revisar el rol de los municipios, en tanto unidad mínima del Estado de mayor cercanía con la población, como un actor relevante en garantizar los derechos de las mujeres y la incorporación del enfoque de género. En tanto unidad mínima del Estado, les corresponde a los municipios hacerse cargo del artículo 5to de la Constitución de la República, que señala: "es deber de los órganos del Estado respetar y promover los derechos garantizados por esta Constitución, así como por los tratados internacionales ratificados por Chile y que se encuentren vigentes".

El SERNAMEG cuenta con programas cuya cobertura no alcanza para todos los municipios del país. Además, por ejemplo, en el caso del Programa Jefas de Hogar, las municipalidades deben aportar con un porcentaje para el funcionamiento del programa, que en el caso de municipios altamente dependientes del Fondo Común Municipal ${ }^{256}$ se hace más complicado de ejecutar. Los municipios destinan recursos de este fondo para la ejecución de planificaciones locales que resultan insuficientes para implementar programas de mediano plazo o no consideran financiamiento para costear los equipos de profesionales que se requieren. Lo mismo ocurre con los Centros de la Mujer (CDM) que administra directamente el SERNAMEG en convenio con las municipalidades. De los 346 municipios que existen en el país, actualmente existen solo 109 $\mathrm{CDM}^{257}$, es decir solo el 31,5\% de los municipios de Chile cuentan con uno.

A lo anterior, cabe sumar la desconexión que existe entre la distintas reparticiones del Estado, ya que en los casos en que el Ministerio de la Mujer y la Equidad de Género a través de los programas del Servicio Nacional de la Mujer y la Equidad de Género no pueda llegar a las comunas, deberían ser los municipios quienes aterricen la política pública nacional en materia de violencia hacia las mujeres, sobre la base de la Ley Orgánica de Municipalidades, que establece dentro de la naturaleza de los municipios - en tanto corporaciones autónomas de derecho público - la finalidad de satisfacer las necesidades de la comunidad local y asegurar su

256 El Fondo Común Municipal establecido en la Ley Orgánica Constitucional de Municipalidades es un mecanismo redistributivo de los ingresos propios entre las municipalidades del país, que consiste en que los mayores aportes de las municipalidades con más recursos se destinan al financiamiento de aquellos municipios con menores recursos, como es el caso de la Municipalidad de Tirúa, que depende casi en un $100 \%$ de este fondo para su funcionamiento.

257 Consulta en página www.sernameg.gob.cl, junio 2020. 
participación en el progreso económico, social y cultural de las respectivas comunas. Algo que es muy complejo cuando la palabra "mujer" aparece una vez en todo el documento de la ley, artículo 4 , letra k, el cual indica que las municipalidades podrán desarrollar funciones relacionadas con "la promoción de la igualdad de oportunidades entre hombres y mujeres".

Organismos internacionales de derechos humanos, como Naciones Unidas y la CEPAL, han hecho reiteradas recomendaciones a los Estados parte a que hagan transversal el enfoque de género en sus políticas nacionales, centrándose en el rol que les compete a los gobiernos locales por su cercanía con la comunidad.

Los municipios pueden llegar a tener mayor agilidad para implementar esos procesos, porque son menos los actores, más pequeñas las distancias para los encuentros, el control social sobre el derecho a la participación y a la toma de decisiones puede activarse rápidamente y esos ejemplos pueden servir como laboratorio de experiencias. (CEPAL, 2016:38)

Estos argumentos se diluyen en la burocracia, no existe supervisión o vigilancia del cumplimiento de los decretos que promulgan los tratados, de tal modo que en aquellos municipios donde no existen Centros de la Mujer, queda a criterio de las gestiones municipales el abordar o no los temas de violencia contra la mujer. A nivel local, y pese a todas las declaraciones mencionadas, observamos el completo desamparo de las mujeres mapuche, campesinas, que sufren violencia en comunas donde la política pública del nivel central no llega. Y los municipios no priorizan presupuesto, por tanto, no se cuenta con profesionales con todas las capacidades que se requieren para abordar las situaciones de violencia que viven las mujeres.

Urge destacar lo escasamente abordados que son los problemas psicosociales por parte del sistema público. Destaca una baja comprensión sobre la importancia del tipo de profesional que se desempeñe en estas áreas, requiriendo formación y especialización en el abordaje de la violencia en contexto de pareja. Algo que parece tan obvio, en muchos municipios no lo es. Muchas veces se termina abordando el tema a la ligera, sumándose una alta rotación de profesionales en las comunas rurales, lo que termina vulnerando doblemente a las personas. En diferentes espacios de diálogo con mujeres del territorio se nos ha relatado que no se confía en las instituciones por experiencias de denuncias que no llegaron a nada, dada la negligencia del Estado en su atención a las mujeres. Esto sería completamente evitable si la institucionalidad comprendiera y se hiciera cargo de la magnitud del problema social y político que se enfrenta cuando se trata de violencia patriarcal.

Es ineludible el desafío de dotar de una arquitectura institucional y de capacidades a los gobiernos locales en beneficio de las mujeres. Se requiere una normativa que garantice que en todos los municipios exista la figura del Centro de la Mujer, conformada por una triada psicosocio-jurídica, es decir, psicóloga, trabajadora social y abogada, con el fin de entregar una atención integral a las mujeres, no solo enfocada en acompañar en una situación de violencia, sino también en acompañar a aquellas que deciden rehacer su vida. Aquí quiero destacar que materializar ese trabajo integral requiere de equipos interdisciplinarios, conducción técnica y fuerte trabajo en red, tres aspectos fundamentales para una atención integral a las víctimas. 
Quienes compartimos el principio básico de que las mujeres víctimas de violencia merecen la mejor atención, debemos reflexionar sobre los modos en que nos aproximamos a la realidad, más cuando esta se encuentra atravesada por una violencia política normalizada. Debemos incidir para que prime un enfoque psicosocial que vincule a las personas con su entorno y el contexto histórico en que se da esta interacción, donde

las emociones, sentimientos, pensamientos, acciones y simbolismos serán producto de esta relación e inseparables de la realidad concreta de vida de las personas. Al incluir el análisis del contexto sociopolítico y sus raíces económicas, este enfoque contribuye al desvelamiento de las relaciones de poder que subyacen en las experiencias de la persona, en sus lazos sociales, en su visión del mundo, así como en el lugar en que se ubica en la estructura social. (Aluna, 2015:10)

Existen situaciones de violencia contra la mujer asociadas a otras problemáticas presentes en los territorios, como consumo problemático de alcohol, que acentúan la situación de violencia y requieren de un acompañamiento integral, coordinado y sostenido en el tiempo. Este acompañamiento, junto con enfrentar el problema, tendrá que enfocarse también en potenciar factores protectores que les permitan a las mujeres salir de la dinámica de violencia.

\section{Respuesta comunitaria a la violencia contra la mujer}

Junto con exigirle al Estado que cumpla lo establecido en la Convención Belém Do Pará, en la Mesa por la No Violencia hemos conversado sobre el desafío de incidencia que tenemos para que la prevención de la violencia contra las mujeres se incorpore en la agenda de las diversas organizaciones de la comuna. La prevención comunitaria de la violencia es un desafío en el que no hemos podido avanzar y lo visualizamos como un trabajo de mediano plazo, que requiere de una planificación seria y de personas que lo dinamicen.

Países hermanos de nuestra ABYA YALA ${ }^{258}$ tienen camino recorrido en el abordaje comunitario de la violencia que enfrentan las mujeres ${ }^{259}$ y pueden orientar las acciones que tenemos que realizar para ir avanzando a un modelo territorial con base en el conocimiento propio: el conocimiento mapuche. Una vez más deberemos hacer uso del nütram como herramienta para resolver nuestros asuntos, e iniciar conversaciones con dirigentes y así, de a poco, ir abonando el terreno para que la cosecha sea instalar el tema de la violencia de pareja en la agenda comunitaria.

Con esperanza vemos la realidad de las ciudades donde las organizaciones de mujeres llevan más camino recorrido en cómo enfrentar la violencia de manera comunitaria. Sin embargo, en el campo es distinto — como hemos argumentado a lo largo de este apartado—, por eso, el desafío también está en cómo, desde nuestros distintos roles y posiciones, aportamos en la construcción de un tejido social sensible ante la violencia contra las mujeres y que tome posición en tanto es una problemática social y de salud.

258 La tierra que habitamos y que hoy se conoce como América a propósito del proceso de colonización.

259 Un análisis desde la antropología sobre esto en el libro Exigiendo JUSTICIA y SEGURIDAD. Mujeres INDÍGENAS y PlURALIDADES LEGALES en AMÉRICA LATINA, coordinado por Rachel Sieder, CIESAS, Ciudad de México, 2017. 


\section{A modo de síntesis}

Estos dos relatos y análisis nos permiten observar los puntos de encuentro de los diversos feminismos - hegemónicos, populares, comunitarios, radicales, campesinos y mapuchefeministas - con las organizaciones de mujeres mapuche que no se identifican necesariamente con los feminismos porque los entienden como parte del proceso de colonización. El derecho de las mujeres a vivir una vida sin violencia es sin duda el principal punto de encuentro, pero incluso allí hay distinciones importantes a propósito de un territorio- cuerpo cruzado por la violencia colonial, empresarial extractivista, institucional militarizada. Las mujeres mapuche no hablan de una sola violencia, hablan en plural para visibilizar todas las estructuras de dominación que cruzan con violencias sus cuerpos.

A propósito de la revuelta social de octubre del 2019 y de cómo se expresaron en los distintos territorios organizados en Chile los saberes insurgentes de las mujeres mapuche, de las mujeres populares y también campesinas, de las experiencias de vida de trabajadoras sexuales, de las trabajadoras de casa particular y tantas otras, muchas feministas nos empezamos a cuestionar las categorías superpuestas a nuestro proyecto político, social, cultural y económico. Asumíamos que el feminismo era anticolonial, antipatriarcal, antirracista, anti capitalista neoliberal y de clase, por ende, enunciarnos feministas suponía que asumíamos como propia la lucha del Pueblo Mapuche y la historia tejida de las mujeres mapuche. Sin embargo, llamarnos feministas a secas implica un trabajo político de densificación de nuestro proyecto/lucha, del que no nos hemos hecho cargo del todo. Es importante asumir que nuestra lucha está cruzada por mucho clasismo, racismo y misoginia y que no todo lo que se llama feminismo lo es. No es fácil desprenderse de la mirada y las prácticas patriarcales, racistas y clasistas en la que muchas hemos sido socializadas. "Darse cuenta" implica un proceso de autobservación constante, de una toma de conciencia no solo objetiva, sino que también subjetiva, para no reproducir los patrones de relacionamiento del patriarcado, del racismo y de lo aspiracional. Este proceso sin duda no tiene fin y, en consecuencia, los adjetivos que ponemos al feminismo que nos mueve nos seguirán acompañando por mucho tiempo.

Independientemente de lo anterior, algunas feministas vemos con esperanza lo que se teje en cada huerta familiar mapuche, en cada hilado y witral Lavjenche, en cada Lawen que prepara una MACHI y en cada cocina de las mujeres mapuche. Somos conscientes de aquellas políticas de resistencia que hoy se vislumbran - a propósito de lo visibles que se hacen durante el Estallido y la revuelta social- como proyectos de vida posible no solo para las y los mapuche, sino que también para tantas y tantos mapuche y no mapuche que queremos caminar hacia el buen vivir en equilibrio, buscando que perdure en el tiempo el ixofillmogen. 


\section{Bibliografía}

AGUILAR, Y. (2019). Femestizajes. Cuerpos y sexualidades racionalizados de ladina-mestizas. F\&G Editores, Ciudad de Guatemala.

ALUNA Acompañamiento Psicosocial (2015). Claves hacia el acompañamiento psicosocial [1. Cuadernillo principal], México. ANAMURI (s.f) Tríptico.

ARAYA CORNEJO, J. (2003). "La invasión de las plantaciones forestales en Chile. Efectos de la actividad forestal en la población indígena mapuche". Documento de trabajo. Santiago. Observatorio Latinoamericano de Conflictos Ambientales

AYLWIN, J., YÁÑEZ, N. y SÁNCHEZ, R. (2013). "Pueblo mapuche y recursos forestales en Chile: devastación y conservación en un contexto de globalización económica". Documento de trabajo. Santiago, Observatorio Ciudadano, Iwgia.

BENAVENTE RIQUELME, M. C.y VALDÉS BARRIENTOS, A. (2014). “Políticas públicas para la igualdad de género: un aporte a la autonomía de las mujeres", Libros de lA CEPAL, N 130 (LC/G.2620-P), Santiago de Chile, Comisión Económica para América Latina y el Caribe (CEPAL).

CEPAL (2016). Territorio e igualdad. Planificación del desarrollo con perspectiva de género. Impreso en Naciones Unidas. Santiago.

HERNÁNDEZ CASTILLO, R. A. (2015). “Hacia una antropología socialmente comprometida desde una perspectiva dialógica y feminista". En Prácticas otras de conocimiento(s). Entre crisis, entre guerras (Tomo II). Chiapas, México.

FOESTER, R. y MONTECINOS, S. (1988) Organizaciones, líderes y Contiendas mapuche (19001970). Ediciones CEM, Santiago de Chile.

GUERRERO, P. (2018) La chakana del corazonar. Desde las espiritualidades y las sabidurías insurgentes de Abya Yala. Universidad Politécnica Salesiana, Quito, Ecuador.

HUENUL COLICOY, S. (2017). "Importancia de la memoria y los saberes locales frente a la profundización del modelo económico". En Revista Anales de la Universidad de Chile. Séptima serie. Número 13/2017. Chile.

KIRKWOOD, J. (2017). Feminarios. Edición Asociación Communes, Viña del Mar, Chile. PAINEMAL MORALES, M. y ÁLVAREZ DÍAZ, A. (Eds) (2016) Mujeres y Pueblos Originarios y resistencias hacia la descolonización. Santiago de Chile, Editorial Pehuén.

PIENSA PRENSA (2020). "Hortaliceras mapuche fueron nuevamente violentas por carabineros en el centro de Temuco". Mayo 4, 2020. Recuperado el 14 de junio de 2020 de: https://piensaprensa.org/2020/05/04/hortaliceras-mapuche-fueron-nuevamen- teviolentas-por-carabineros-en-el-centro-de-temuco/

PNUD-ONU Mujeres (2013). El compromiso de los Estados: planes y políticas para erradicar la violencia contra las mujeres en América Latina y el Caribe. 
SIEDER, R. (Coord.) (2017) Exigiendo justicia y seguridad. Mujeres indígenas y pluralidades legales en América latina. Publicaciones de la Casa Chata, CIESAS, Ciudad de México. 